\title{
Biodiesel production performance estimation from simple viscosity measurements
}

\author{
L. Díaz, M.E. Borges* and A. Brito \\ Chemical Engineering Department \\ University of La Laguna \\ Avda. Astrofísico Fco. Sánchez s/n, La Laguna, Tenerife, Canary Island, 38200, Spain \\ Corresponding author: eborges@ull.es
}

\begin{abstract}
In a biodiesel production industry a quick monitorization of the reaction extent achieved in the process it is important. The usual way to determine the reaction yield is to analyze the FAME content in the biodiesel reaction product. Analytic methods used, mainly gas chromatography, require previous sample treatment or tedious calibrations. Recently, less complicated analytic methods (nuclear magnetic resonance, infrared spectrophotometry) have been developed but they require costly equipment and analysis. The aim of this paper is to develop a cheap and fast method in order to quantify the FAME content in the reaction mixture from simple dynamic viscosity measurements and then the transesterification reaction yield. Therefore, experimentally obtained correlations from biodiesel proceeding of several oil feedstocks are presented in order to estimate the biodiesel FAME content from its dynamic viscosity, a fast determination parameter.
\end{abstract}

\section{Key words}

Biodiesel, FAME, NMR, dynamic viscosity

\section{Introduction}

Biodiesel, an alternative diesel fuel, is made from renewable biological production such as vegetables oils and animal fats [1]. Biodiesel production is a very modern and technological area for researchers. Its relevance comes from petroleum price increasing and from biodiesel environmental advantages [2], mainly diminishing global warming gases levels such as carbon dioxide. Moreover, its use has also showed improvements on engine exhaust emissions. For instead, combustion of biodiesel decreases carbon monoxide (CO) emissions by $46.7 \%$, particulate matter emissions by $66.7 \%$ and unburned hydrocarbons by $45.2 \%$ [3]. Additionally, biodiesel is non-toxic, making it useful for transportation applications in highly sensitive environments, such as marine ecosystems and mining enclosures [4]. Transesterification is one of the most commercially useable methods to produce biodiesel [5]. Transesterification is a reversible reaction of a fat or oil with alcohol (methanol or ethanol) to form fatty acid alkyl esters (FAME) and glycerol in presence of a suitable catalyst.

The biodiesel production from vegetables oils is relatively simple using alkaline homogeneous transesterification, with conversion efficiency higher 98\% [6]. However, the homogeneous catalyzed transesterification reaction has some disadvantages as it consumes large amount of water for wet washing to remove the salt produced from the neutralization process [7]; besides, the catalyst cannot be reutilized, they favour the formation of stable emulsions making the methyl esters (biodiesel product) separation difficult, glycerol is obtained as an aqueous solution of relatively low purity and the reaction becomes very sensitive to the presence of water and free fatty acids [8,9]. An alternative path for biodiesel production involves the use of heterogeneous catalysts. A heterogeneous catalyst can be easily removed from the produced biodiesel [10] without the use of water as washing agent and it can be reused for further reactions.

Biodiesel can be commercialized as pure biofuel or blending stock for diesel fuels, it must meet a set of requirements defined in standard specifications for a safe and satisfactory engine operation, one of these specifications is the content of fatty acid methyl esters (FAME). Besides, this parameter indicates the performance of the transesterification reaction for biofuel production from vegetable oils. There are several methods to determinate FAME content in biodiesel samples (chromatography, nuclear magnetic resonance 
spectroscopy and FTIR spectroscopy); however, they take long times and high cost for FAME content determination. From a practical point of view, in industrial biodiesel production is usually necessary to estimate the FAME value quickly.

The viscosity is the basic parameter that reflects the extent of the reaction of biodiesel production [11] because an important decrease in vegetable oil viscosity is produced when oil is converted to FAME (usually from 25-40 cSt to 4-5 cSt, depending on the type of oil used as feedstock). Then, the viscosity is directly related to the fatty acid methyl esters content of the biodiesel product.

Dynamic viscosity value can be determinated by a fast, cheap and no destructive analysis with low cost equipment. Therefore, derived from our studies on the use of several solids as catalyst for the transesterification of vegetal oils with methanol, we developed a reliable and fast method to monitor the transesterification reaction development, concluding correlations in order to determine the methyl esters content in biodiesel from its dynamic viscosity value.

\section{Experimental}

The biodiesel product in this study was produced by transesterification of three feedstocks: sunflower oil, fried oil and Jatropha Curcas oil. The first one was commercial edible-grade sunflower oil purchased from the market and used without further purification, the second one was waste oil from food frying process and it was previously filtered in order to remove suspended solids, the third one was oil extracted directly from Jatropha seeds. The main properties of these oils are shown in Table I. Methanol used was analytical grade obtained from Scharlau.
Heterogeneous and homogeneous catalyzed transesterification reactions of the biodiesel product obtained were performed in a jacketed glass reactor (250 $\mathrm{ml}$ ) with methanol reflux. In order to obtain biodiesel reaction products with a broad range of reaction yields, several transesterification reactions were carried out with the operation variables range showed in Table I.

Different solids as heterogeneous catalysts were used for heterogeneous reactions: natural materials (pumice and volcanic ashes), commercial catalysts (Zeolite $\mathrm{X}$ and Zeolite Y), synthesized catalyst $\left(\mathrm{La}_{2} \mathrm{O}_{3}\right.$, hydrotalcite, $\mathrm{Mg} / \mathrm{La}$ mixed oxide) and $\mathrm{KOH}$ was used as catalyst for homogeneous reactions.

In all cases, the catalyst was separated from the reaction mixture after reaction and the liquid product obtained was evaporated to remove methanol excess, and then the upper phase containing fatty acid methyl esters (biodiesel phase) and the lower phase containing glycerol were separated in a decantation funnel. The biodiesel product from each reaction was collected and its dynamic viscosity was measured using a rotational viscometer VISCO STAR Plus L. Moreover, the same biodiesel sample was analyzed by ${ }^{1} \mathrm{H}$ Nuclear Magnetic Resonance (NMR) spectrometry (Bruker Avance 400) in order to estimate the fatty acid methyl ester yield using following formula [12]:

$$
\text { Yield }(\%)=\frac{2 A_{1}}{3 A_{2}} .100
$$

where $A_{1}$ and $A_{2}$ are the areas of the methoxy and the methylene protons, respectively. This relevant signals chosen for integration are those of methoxy groups in the methyls esters at $3.7 \mathrm{ppm}$ (singlet) and of the $\alpha$-carbonyl methylene groups present in all fatty ester derivatives at 2.3 ppm (triplet).

Previously, biodiesel samples were dried with anhydrous $\mathrm{Na}_{2} \mathrm{SO}_{4}$ and, then submitted to NMR analysis in deuterated chloroform $\left(\mathrm{CDCl}_{3}\right)$ using tetramethylsilane (TMS) as internal standard.

Table I. Oil feedstocks properties and operation variables range.

\begin{tabular}{|l|c|c|c|}
\hline & Sunflower oil & Waste oil & Jatropha Curcas oil \\
\hline \multicolumn{2}{|c|}{ Property } & \multicolumn{2}{|c|}{} \\
\hline Density at $15^{\circ} \mathrm{C}\left(\mathrm{g} / \mathrm{cm}^{3}\right)$ & 0.924 & 0.930 & 0.923 \\
Kinematic viscosity at $40^{\circ} \mathrm{C}(\mathrm{cSt})$ & 29.4 & 34.5 & 27.6 \\
Acid value $(\mathrm{mg} \mathrm{KOH} / \mathrm{g})$ & 0.17 & 2.02 & 2.95 \\
Iodine index (g Iodine/100 g sample) & 138.8 & 122.3 & 121.0 \\
Turbidity (NTU) & 2.24 & 9.99 & 3.59 \\
\hline \multicolumn{1}{|c|}{ Operation variables range } & \multicolumn{3}{|c|}{} \\
\hline Temperature $\left({ }^{\circ} \mathrm{C}\right)$ & $50-60$ & $55-60$ & $55-60$ \\
Reaction times (min) & $30-240$ & $30-240$ & $150-240$ \\
Methanol/oil molar ratio & $6: 1-24: 1$ & $18: 1-36: 1$ & $18: 1-24: 1$ \\
Catalyst amount (wt.\%) & $4-20$ & $20 \%$ & $20 \%$ \\
\hline
\end{tabular}




\section{Results and discussion}

Several materials were proven as heterogeneous catalysts to carry out the transesterification reaction: Pumice (particles, 1.40-3.0 mm), Zeolite X (microspheres, 400$800 \mu \mathrm{m})$, Zeolite Y (Akzo Nobel), natural volcanic ashes (VA) (particles, 1.40-1.80 mm) from volcanic zone soil in Tenerife (Canary Islands), $\mathrm{La}_{2} \mathrm{O}_{3}$ supplied by Panreac, Hydrotalcite $\left[\mathrm{Mg}_{6} \mathrm{Al}_{2}(\mathrm{OH})_{16}\right]\left(\mathrm{CO}_{3}\right) \cdot 4 \mathrm{H}_{2} \mathrm{O}$ supplied by Aldrich and $\mathrm{Mg} / \mathrm{La}$ mixed oxide.

\section{Conclusions}

In summary, we have demonstrated that it is possible to develop a fast fatty acid methyl esters content estimation from viscosity measures in biodiesel samples. This method is suitable for the determination of methyl ester contents considering different sources of vegetable oils.

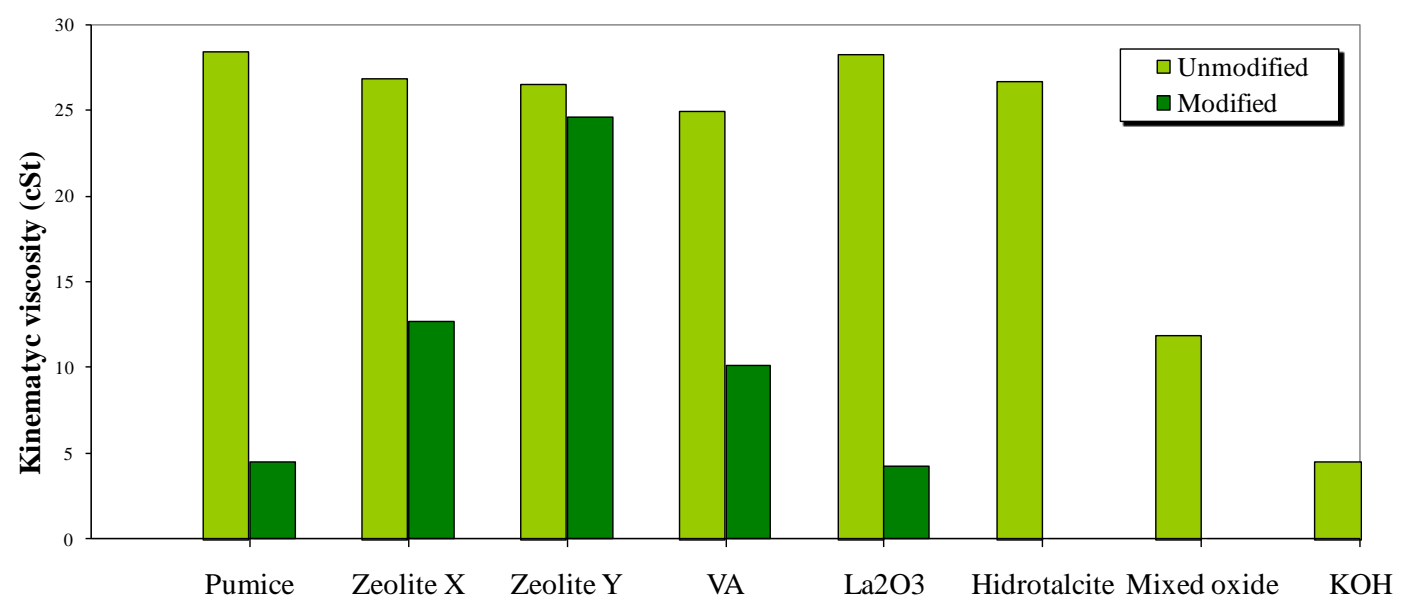

Fig.1. Catalytic activity of homogeneous and heterogeneous catalysts.

In order to enhance their catalytic activity, the potentially catalytic materials were subjected to different treatments related to their individual nature and structure (modified catalyst). Moreover $\mathrm{KOH}$ was used as conventional homogeneous catalyst. Figure 1 shows the viscosity of the biodiesel product obtained when transesterification reaction was carried out with each catalyst using several operation variables in the range showed in Table I.

Figure 2 shows as an example the ${ }^{1} \mathrm{H}-\mathrm{NMR}$ spectra obtained from oil and biodiesel samples analysis.

It can be seen that the only significant change in the spectra is the appearance of a new singlet peak at 3.7 ppm when fatty acid methyl esters are produced. All other peaks related to aliphatic and olefinic hydrogens of the alkyl chain remain in the same position being in good agreement with the values published in bibliography [13, 14].

In figure 3, the biodiesel viscosity value is plotted v.s. the FAME yield of each biodiesel sample. As can be seen, similar correlation has been obtained for biodiesel product obtained from both vegetal oils studied and from waste oil with a broad operation variables range. For practical purposes, both graphs are applicable for predicting biodiesel FAME yields from its viscosity, measured at $40^{\circ} \mathrm{C}$ in centipoises.

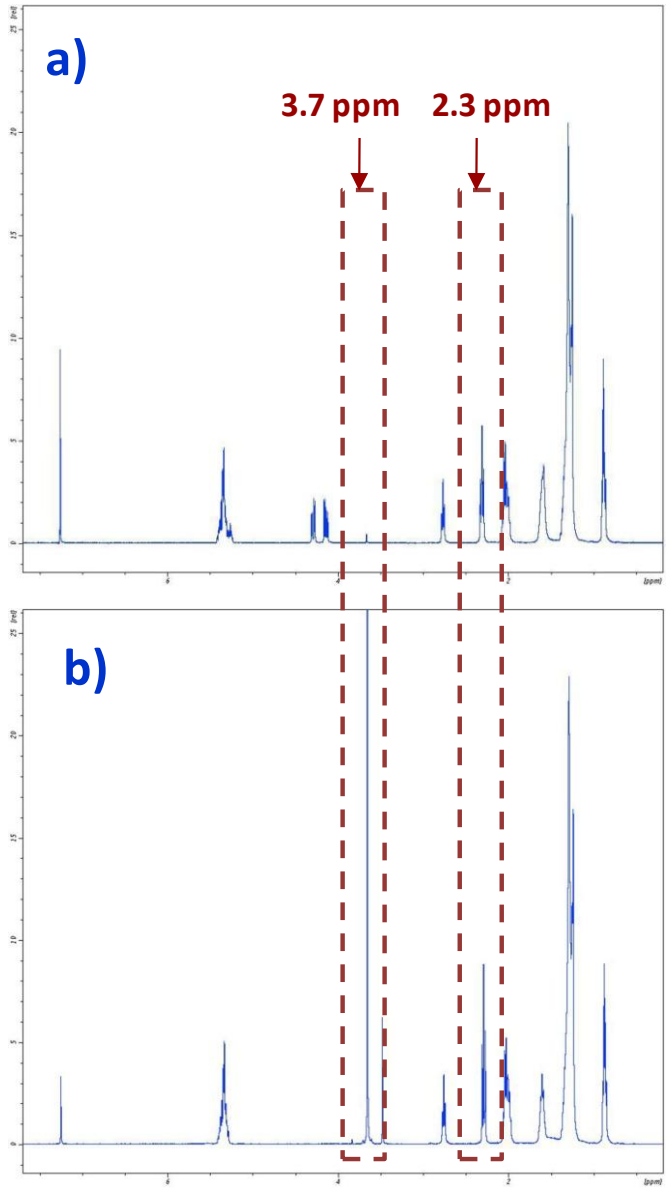

Fig.2. ${ }^{1}$ H-NMR spectra: (a) sunflower oil, (b) biodiesel sample. 

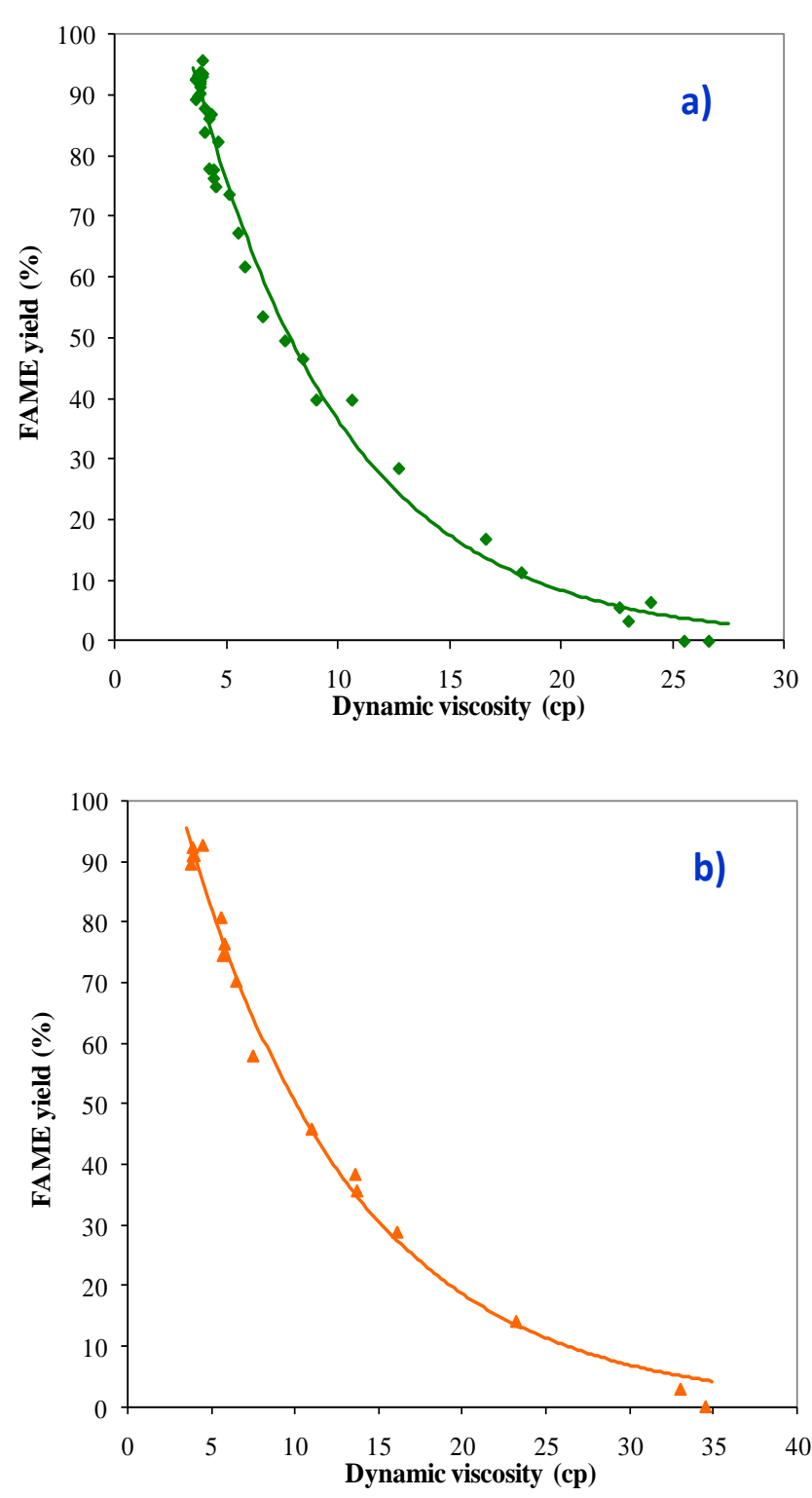

Fig.3. Fatty acid methyl esters content vs biodiesel samples dynamic viscosity: (a) Sunflower and Jatropha oil, (b) waste oil.

\section{Acknowledgement}

The authors acknowledge a research grant support by Programa de FPU del Ministerio de Educación, Spain.

\section{References}

[1] Balat, M.; Balta, H. Progess in biodiesel processing, processing, Applied Energy 87, 1815-1835, 2010.

[2] Marcheti, J.M.; Miguel, U.V.; Errazu, A.F. Possible methods for biodiesel production, Renewable Sustainable Energy Reviews 11, 1300-1311, 2007.

[3] Shumaker, J.L.C.; Crofcheck, S.A.; Tackett, E.S; Jimenez, M.; Crocker, Biodiesel production from soybean oil using calcined $\mathrm{Li}$-Al layered double hydroxide catalysts, Catalysis Letter 115, 56-61, 2007.

[4] Helwani, Z.; Othman, M.R.; Aziz, N.; Fernando, W.J.N.; Kim, J. Technologies for production of biodiesel focusing on green catalytic techniques: a review, Fuel Processing Technologies 90, 1502-1514, 2009.

[5] Zabeti, M.; Wan Dau, W.M.A; Aroua, M.K. Activity of solid catalysts for biodiesel production: a review, Processing Technologies 90, 770-777, 2009.

[6] Canakci, M.; Sanli, H. Biodiesel production from various feedstock and their effects on the fuel properties, Journal of Industrial Microbiology and Biotechnology 35, 431-441, 2008.

[7] Janaun, J.; Ellis, N. Perspectives on biodiesel as a sustainable fuel, Renewable Sustainable Energy Reviews 14, 1312-1320, 2010.

[8] Arzamendi, G.; Campo, I.; Arguiñarena, E.; Sánchez, M.; Montes, M.; Gandía, L.M. Synthesis of biodiesel with heterogeneous $\mathrm{NaOH} /$ alumina catalysts: comparison with homogeneous $\mathrm{NaOH}$, Chemical Engineering Journal 134, 123-130, 2007

[9] Wen, Z.; Yu, X.; Tu, S.; Yan, J. ; Dahlquist, E. Synthesis of biodiesel from vegetable oil with methanol catalyzed by $\mathrm{Li}$ doped magnesium oxide catalysts, Applied Energy 87, 743 748,2010

[10]Baroutian, S.; Aroua, M.K.; Raman, A.A.A; Sulaiman, N.M.N. A packed bed membrane reactor for production of biodiesel using activated carbon supported catalyst, Bioresource technology, in press, 2010.

[11]Brito, A.; Borges, M.E.; Garín, M.; Hernández, A. Biodiesel production from waste oil using $\mathrm{Mg}$.Al layered double hydroxide catalyst, Energy and Fuels 23, 2952-2958, 2009.

[12]Gelbard, G.; Brès, O.; Vargas, R.M.; Vielfaure, F.; Schuchardt, U.F. ${ }^{1} \mathrm{H}$ Nuclear Magnetic Resonance determination of the yield of the transesterification of rapeseed oil with methanol, Journal of the American Oil Chemist's Society 72 (10), 1239-1241, 1995.

[13]Jin, F.; Kawasaki, K.; Kishida, H.; Tohji, K.; Moriya, T.; Enomoto, H. NMR spectroscopic study on methanolysis reaction of vegetable oil, Fuel 86, 1201-1207, 2007.

[14]Morgenstern, M.; Cline, J.; Meyer, S.; Cataldo, S. Determination of the kinetics of biodiesel production using proton nuclear magnetic resonance spectroscopy $\left({ }^{1} \mathrm{H}\right.$ NMR), Energy Fuels 20, 1350-1353, 2006. 